\title{
Novel Combined Spectral Indices Derived from Hyperspectral and Laser-Induced Fluorescence LiDAR Spectra for Leaf Nitrogen Contents Estimation of Rice
}

\author{
Lin Du ${ }^{1,2}$, Jian Yang ${ }^{1}$, Bowen Chen ${ }^{3, *}{ }^{\mathbb{C}}$, Jia Sun ${ }^{1}$, Biwu Chen ${ }^{3}{ }^{(\mathbb{C}}$, Shuo Shi ${ }^{3,4}$, Shalei Song ${ }^{5}$ \\ and Wei Gong ${ }^{3,4}$ \\ 1 School of Geography and Information Engineering, China University of Geosciences (Wuhan), 388, Lumo \\ Road, Wuhan 430074, China; dulin@cug.edu.cn (L.D.); yangiian@cug.edu.cn (J.Y.); sunjia@cug.edu.cn (J.S.) \\ 2 Artificial Intelligence School, Wuchang University of Technology, 16, Jiangxia Avenue, Wuhan 430223, China \\ 3 State Key Laboratory of Information Engineering in Surveying, Mapping and Remote Sensing, Wuhan \\ University, 129, Luoyu Road, Wuhan 430079, China; cbw_think@whu.edu.cn (B.C.); \\ shishuo@whu.edu.cn (S.S.); weigong@whu.edu.cn (W.G.) \\ 4 Collaborative Innovation Center of Geospatial Technology, 129, Luoyu Road, Wuhan 430079, China \\ 5 State Key Laboratory of Magnetic Resonance and Atomic and Molecular Physics, Wuhan Institute of Physics \\ and Mathematics, Chinese Academy of Sciences, 30, Xiaohongshan West, Wuhan 430071, China; \\ songshalei@gmail.com \\ * Correspondence: chenbowen1204@whu.edu.cn; Tel.: +86-134-7707-9854
}

Received: 3 December 2019; Accepted: 1 January 2020; Published: 4 January 2020

\begin{abstract}
Spectra of reflectance $\left(S_{r}\right)$ and fluorescence $\left(S_{f}\right)$ are significant for crop monitoring and ecological environment research, and can be used to indicate the leaf nitrogen content (LNC) of crops indirectly. The aim of this work is to use the $S_{r}-S_{f}$ features obtained with hyperspectral and laser-induced fluorescence LiDAR (HSL, LIFL) systems to construct novel combined spectral indices $\left(N C I_{H-F}\right)$ for multi-year rice LNC estimation. The $N C I_{H-F}$ is in a form of $\mathrm{FWs}^{*} \Phi+\mathrm{GSIs}^{*} \Phi$, where $\Phi$ is the $S_{r}-S_{f}$ features, and FWs and GSIs are the feature weights and global sensitive indices for each characteristic band. In this study, the characteristic bands were chosen in different ways. Firstly, the $S_{r}-S_{f}$ characteristics which can be the intensity or derivative variables of spectra in 685 and $740 \mathrm{~nm}$, have been assigned as the $\Phi$ value in $N C I_{H-F}$ formula. Simultaneously, the photochemical reflectance index (PRI) formed with 531 and $570 \mathrm{~nm}$ was modified based on a variant spectral index, called $P R I_{\text {fraction, }}$, with the $S_{f}$ intensity in $740 \mathrm{~nm}$, and then compared its potential with $N C I_{H-F}$ on LNC estimation. During the above analysis, both $N C I_{H-F}$ and $P R I_{\text {fraction }}$ values were utilized to model rice LNC based on the artificial neural networks (ANNs) method. Subsequently, four prior bands were selected, respectively, with high FW and GSI values as the ANNs inputs for rice LNC estimation. Results show that FW- and GSI-based $\mathrm{NCI}_{\mathrm{H}-\mathrm{F}}$ are closely related to rice $\mathrm{LNC}$, and the performance of previous spectral indices used for LNC estimation can be greatly improved by multiplying their FWs and GSIs. Thus, it can be included that the FW- and GSI-based $\mathrm{NCI}_{\mathrm{H}-\mathrm{F}}$ constitutes an efficient and reliable constructed form combining HSL $\left(S_{r}\right)$ and LIFL $\left(S_{f}\right)$ data together for rice LNC estimation.
\end{abstract}

Keywords: hyperspectral LiDAR; laser-induced fluorescence LiDAR; combined spectral index; leaf nitrogen content

\section{Introduction}

Nitrogen $(\mathrm{N})$ is an essential nutrient for crops, such as rice, and an indispensable constituent element for plants [1]. Proper $\mathrm{N}$ intake improves the conversion efficiency of light energy during the 
photosynthesis process, thereby promoting rice growth. However, $\mathrm{N}$ surplus can not only inhibit the healthy development of rice, but can also cause various environmental problems, such as water and air pollution [2]. Moreover, leaf nitrogen content (LNC) is linearly related to photosynthesis capacity (e.g., the maximum carboxylation capacity, $\mathrm{V}_{\mathrm{cmax}}$ ) [3,4]. Therefore, an accurate and reliable estimation of $\mathrm{N}$ content is of great significance to agriculture monitoring (e.g., the productivity, water use), as well as in current and future ecological environment research $[5,6]$.

Spectra obtained by remote sensing technologies have been widely used in monitoring $\mathrm{N}$ contents or the growth status of vegetation (GSV) because of their high spectral resolution and close relationships with biochemicals, such as chlorophyll (Chl), N, water, and biomass [7-11]. Reflectance spectrum $\left(S_{r}\right)$ is a commonly used feature for characterizing GSV [12,13]. A positive correlation is usually observed between $S_{r}$ and $\mathrm{N}$ contents in a visible band, but the correlation becomes negative in the near infrared band $[14,15]$. This tendency is closely related with the photosynthesis process in vegetation leaf [16]. Many scholars have constructed correlation models based on $S_{r}$ or its spectral variables, including spectral index (normalized differential vegetation index, NDVI; ratio index, RI), and derivative spectrum, to obtain accurate $\mathrm{N}$ contents and then predict crop yield [17-20]. Du et al. [21] successfully used $S_{r}$ features collected with hyperspectral LiDAR (HSL) system to estimate the LNC of rice through support vector machine (SVM) method. Another feature spectrum that can accurately indicate GSV is Chl fluorescence spectrum $\left(S_{f}\right)$, which is mainly produced during photosynthesis II (PSII) in chloroplast [22]. In PSII, a parameter called conversion efficiency of primary light energy can be reduced because of the lack of LNC, whereas being important for $S_{f}$ property [23,24]. As shown in $S_{f}$ curves, the intensity in 685 and $740 \mathrm{~nm}$ increases with LNC, which are two critical feature bands for vegetation monitoring [25-28]. Thus, LNC estimation can be efficiently conducted by $S_{f}$ feature analysis. Guo et al. [29] analyzed the effect of $\mathrm{N}$ fertilization on $S_{f}$ feature and wheat flag leaf yield to manage rational $\mathrm{N}$ fertilization for wheat. Yang et al. [30] successfully predicted the pepper LNC by extracting the characteristic parameters of $S_{f}$. Yang et al. [31] used $S_{f}$ features obtained with laser-induced fluorescence LiDAR (LIFL) to estimate rice LNC, obtaining satisfactory results via artificial neural network (ANN) analysis.

Given that both $S_{r}$ and $S_{f}$ can codetermine the vegetation LNC efficiently, their combination is necessary for the accurate monitoring of GSV [32-34]. By using modeled and measured data, Pablo et al. [35,36] suggested to develop a correlation algorithm based on $S_{r}-S_{f}$ features on leaf level, and then used it to analyze the obtained $S_{r}$ features with CASI sensor in the canopy level. By using HSL and LIFL systems, Shi et al. [37] successfully estimated rice LNC by selecting more than 12 independent $S_{r}-S_{f}$ variables with several regression methods, including SVM, ANNs and partial least squares (PLS). Yang et al. [38] performed similar works using $S_{r}$ collected with ASD (Analytical Spectral Devices, Inc., Boulder, CO, USA) and $S_{f}$ with LIFL. They randomly divided $S_{r}-S_{f}$ variables into three equal parts and used principal component analysis (PCA) combined with an ANN method to model rice LNC. Their results showed that the proposed combination of $S_{r}-S_{f}$ could greatly improve the accuracy of LNC estimation model. However, the $S_{r}$ and $S_{f}$ variables were considered as single inputs of PCA-ANNs model simply, but a necessary physical explanation on the combined spectral variables was lacking in their experiment. Thus, Robert et al. [39] directly used the ratio of the $S_{r}$ and $S_{f}$ to measure the concentration of the fluorophore in the turbid liquid and explore the efficient combined forms of $S_{r}-S_{f}$ variables for practical application. Furthermore, Shi et al. [40] constructed some spectral indices (SIs) of $S_{r}-S_{f}$ in some special feature bands, including 685 and $740 \mathrm{~nm}$, for LNC estimation of rice. These SIs were derived from HSL and LIFL data in two types of combined forms, including the ratio of $S_{r}-S_{f}$ and a form similar to NDVI.

In this work, a novel combined SI form $\left(\mathrm{NCI}_{\mathrm{H}-\mathrm{F}}\right)$ based on HSL and LIFL systems was derived for LNC estimation in some prominent bands of $S_{r}$ and $S_{f}$. These $N C I_{H-F}$ are linearly connected with a special factor calculated through feature weights (FWs) and global sensitivity analysis, respectively. The FWs are determined by a divergence of each class divided according to vegetation species and biochemical contents [41-43]. In this manner, feature bands with high FWs which means a high 
contribution to LNC, can be considered in the estimation of LNC in a form of $\mathrm{FWs}^{*} \Phi$, where $\Phi$ is the intensity or derivative variables of $S_{r}$ and $S_{f}$. Global sensitivity analysis can generate global sensitivity indices (GSIs) that present the contributions from multiple interest biochemicals, such as Chl, water and so on, to the changes in each feature band [44,45]. GSIs were also formed in a similar way as GSIs* $\Phi$ for each prior ranked band. Then, the above FW- and GSI-based items are integrated finally in a form of $\mathrm{FWs}^{*} \Phi+\mathrm{GSIs}^{*} \Phi$ for LNC estimation.

This work aims to construct a combined SIs for LNC estimation of rice by using $S_{r}-S_{f}$ features obtained with HSL and LIFL systems. The rice leaf sampling and the data measurements of $S_{r}-S_{f}$ are described in Section 2. An overview of the analysis methods in this study can be found in Section 3.1, and then two factor-calculated methods (FW analyses and global sensitivity analyses) are respectively presented in Section 3.2. Responding to the Results section, the $N C I_{H-F}$ models of rice LNC based on these two methods in specified bands $(685$ and $740 \mathrm{~nm}$ ) are presented in Sections 4.1 and 4.2 respectively. The regression algorithm is ANN which has been described in Section 3.3. Being different with the designated variables in 685 and $740 \mathrm{~nm}$, the first four bands ranked according to the FWs and GSIs are selected successively for the prediction of rice LNC (Section 4.3). Comparisons and discussions of the model performance are provided in Section 5, followed by the conclusions drawn in Section 6.

\section{Experimental Materials and Data Measurements}

\subsection{Samples Preparation}

Leaf samples were collected in the Jianghan Plain of China $\left(29^{\circ} 58^{\prime} \mathrm{N}\right.$ to $31^{\circ} 22^{\prime} \mathrm{N}, 113^{\circ} 41^{\prime} \mathrm{E}$ to $115^{\circ} 05^{\prime} \mathrm{E}$ ) during the different growth stages of rice, namely, the booting and heading stages on 15 July 2014 and 1 August 2014 and in the tillering stage on 21, 22, 24, and 26 July 2015. The growth stages of rice were labeled in subsequent text with 2014-B, 2014-H and 2015-T respectively. The experiment area belongs to the subtropical monsoon zone, which has a mild climate, mean precipitation of 856-1070 $\mathrm{mm}$ and temperature of $15.5^{\circ} \mathrm{C}$ [46]. The rice varieties were Yongyou 4949 (2014) and Yangliangyou 6 (2015). Different levels of urea fertilizer were used in the experimental fields which could be found in the study of Shi et al. [37] in detail. Three fertilization repetitions were performed for each cultivation condition in 2014 and 2015. The sample sizes in this experiment were 120 for 2014 and 144 for 2015. The rice leaves were the second ones from the canopy of the rice plant, which were destructively sampled by randomly cutting six leaves for each experimental field.

\subsection{LiDAR Systems and Data Measurement}

The HSL system used in this work consisted of some fundamental components, including laser emission, photovoltaic receiving and conversion and the data processing section (Figure 1). The light emission section of the HSL mainly contained a supercontinuum laser source (SuperK EXTREME, NKT Photonics Inc., DEN), which can generate a wide-band laser with a frequency of $20-40 \mathrm{kHz}$, an average output power of $100 \mathrm{~mW}$, a broadband spectrum white light of $\sim 450-2400 \mathrm{~nm}$ and a pulse duration of $1-2 \mathrm{~ns}[47,48]$. The data collected by HSL represented the characteristic spectrum of the target in a range of 538-910 nm with the spectral resolution of $12 \mathrm{~nm}$ based on the APD array, which consisted of 32 separated channels with a spectral sensitive range of 300-920 nm (D1 in Figure 1). The components of LIFL system were similar to those of HSL, and the only difference with HSL was that the LIFL system had the ultraviolet excitation light source $(355 \mathrm{~nm}, 20 \mathrm{~Hz}$, Surelite OPO PLUS, USA) and a spectrograph with ICCD camera (D2 in Figure 1, Princeton Instrument SP2500i, USA) as the section of laser emission, and photovoltaic receiving and conversion, respectively. The laser source for LIFL is an Nd: YAG which has an output power of $1.5 \mathrm{~mJ}$ and width per pulse of $5 \mathrm{~ns}$. The spectrograph can be controlled along with the direct commands through its USB or RS-232 port, so as to scan and then obtain $S_{f}$ characteristics with a wide-range $(360-800 \mathrm{~nm})$ and high spectral resolution $(0.5 \mathrm{~nm})$. In order to eliminate the effects of light reflected from the laser, we placed a $355 \mathrm{~nm}$ long-pass edge filter (M3 in Figure 1) between the spectrograph and the optics fiber during $S_{f}$ collection. The filter was 
shunted to the other side during the measurement of $S_{r}$. These two LiDAR systems, which had the same optics design, were used in collecting and focusing light signals into an achromatic telescope (with a diameter of $200 \mathrm{~mm}$, MEADE, USA), and then transmiting the light signals reflected from the target surface to two photo-sensitive receiver ports on a SP2500i spectrometer (D1 for $S_{r}$, red and D2 for $S_{f}$, blue in Figure 1) through an optics fiber for photovoltaic conversion. Further details about the systems can be found in the study of Du et al. [40] and Yang et al. [49].

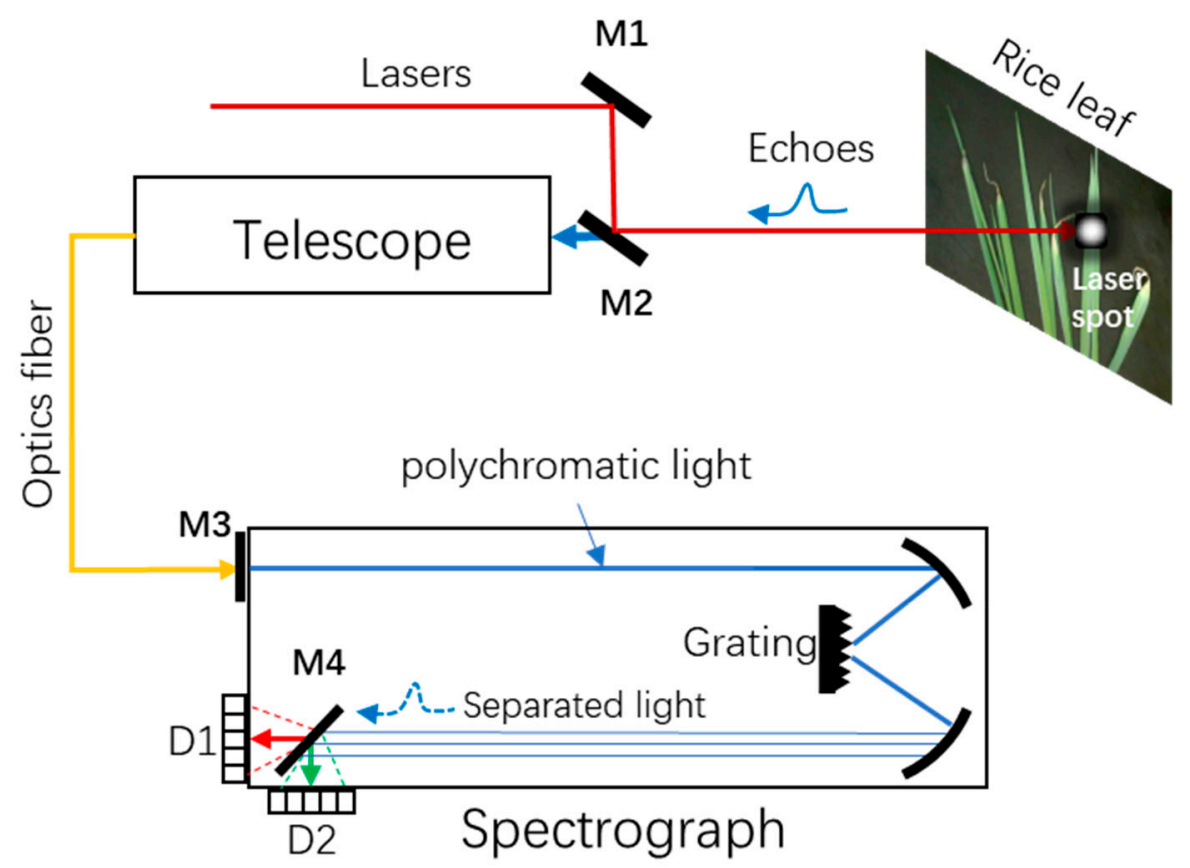

Figure 1. LiDAR systems used for reflectance and fluorescence spectra measurement.

With these two LiDAR systems, spectra of $S_{r}$ and $S_{f}$ were measured at three different positions off the rice leaf vein for one sample, and five replications were carried out at the same position. Then, the characteristic spectra for one leaf were represented with the average of 15 spectra obtained by the above process. The laser spots of HSL and LIFL resided onto the measured position perpendicularly and completely.

As shown in Figure 2, differences among rice LNC levels are easily distinguished on the basis of some feature positions on the $S_{r}$ and $S_{f}$ curves measured by HSL (Figure 2a) and LIFL (Figure 2b) systems respectively. After the collection of the spectra, LNC values were determined using the Kjeldahl method [50], and then weighted and expressed as milligrams per gram of leaf dry matter. The LNC values in 2014 ranged from 2.5 to $4 \mathrm{mg} / \mathrm{g}$, with an average (Ave) of $3.34 \mathrm{mg} / \mathrm{g}$ and standard deviation (SD) of $0.27 \mathrm{mg} / \mathrm{g}$. In 2015, the LNC ranging from $1.1 \mathrm{mg} / \mathrm{g}$ to $4.4 \mathrm{mg} / \mathrm{g}$ had an Ave value of $2.84 \mathrm{mg} / \mathrm{g}$ and SD value of $0.61 \mathrm{mg} / \mathrm{g}$. 

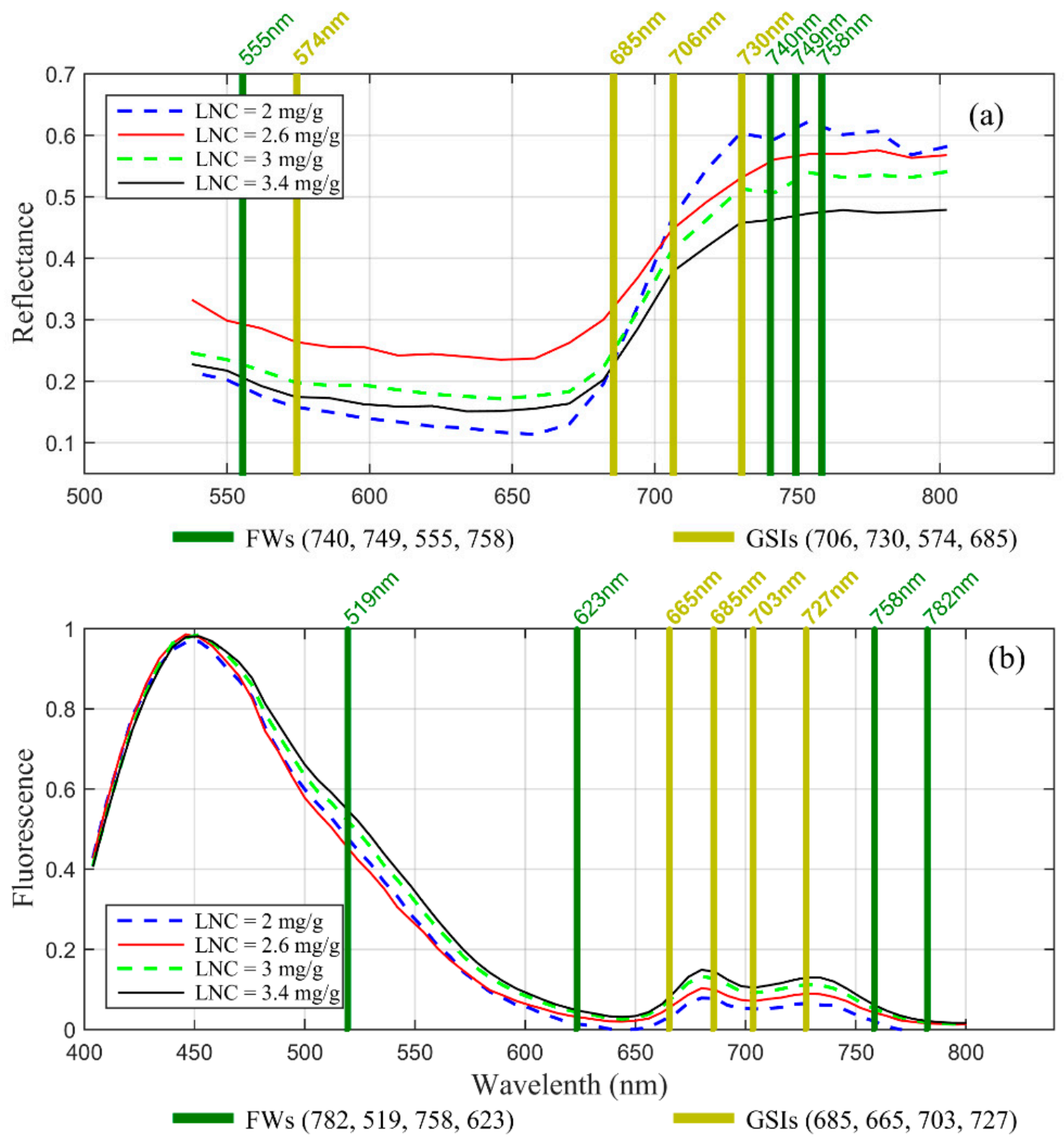

Figure 2. Spectra of $S_{r}$ and $S_{f}$ collected with (a) Hyperspectral LiDAR and (b) laser-induced fluorescence LiDAR system under different rice LNCs. Stripes on $S_{r}$ and $S_{f}$ curves represent prior band distribution ranked based on the FW and GSI values, which will be discussed in the Results section.

\section{Methods}

\subsection{Overview of the Analysis Method}

In this study, a SIs, called $N C I_{H-F}$, was constructed to estimate the rice LNC. This kind of SIs links the HSL and LIFL spectra to LNC through two factors $\left(\omega_{1}, \omega_{2}\right.$ in Equation (1)) which are closely related to the characteristic bands.

$$
N C I_{H-F}=\omega_{1} \Phi_{\mathrm{HSL}}+\omega_{2} \Phi_{\mathrm{LIFL}}
$$

On the basis of two calculation methods for these factors, the analysis methods in this study were organized as shown in Figure 3: (I) FW-based $N C I_{H-F}$ were utilized for estimation of rice LNC, and then (II) utilized based on GSIs. The results were respectively summarized in Sections 4.1 and 4.2. (III) Finally, four characteristic bands from $S_{r}$ and $S_{f}$ data were respectively ranked and then selected based on the values of FW and GSI for the calculation of $N C I_{H-F}$, rather than designating them in $685,740 \mathrm{~nm}$. The estimation results were showed in Section 4.3. Meanwhile, a modified SI 
named PRI fraction (Equations (7) and (8) in Section 4.1) [51] was proposed in steps (I) and (II) for the comparison experiment.

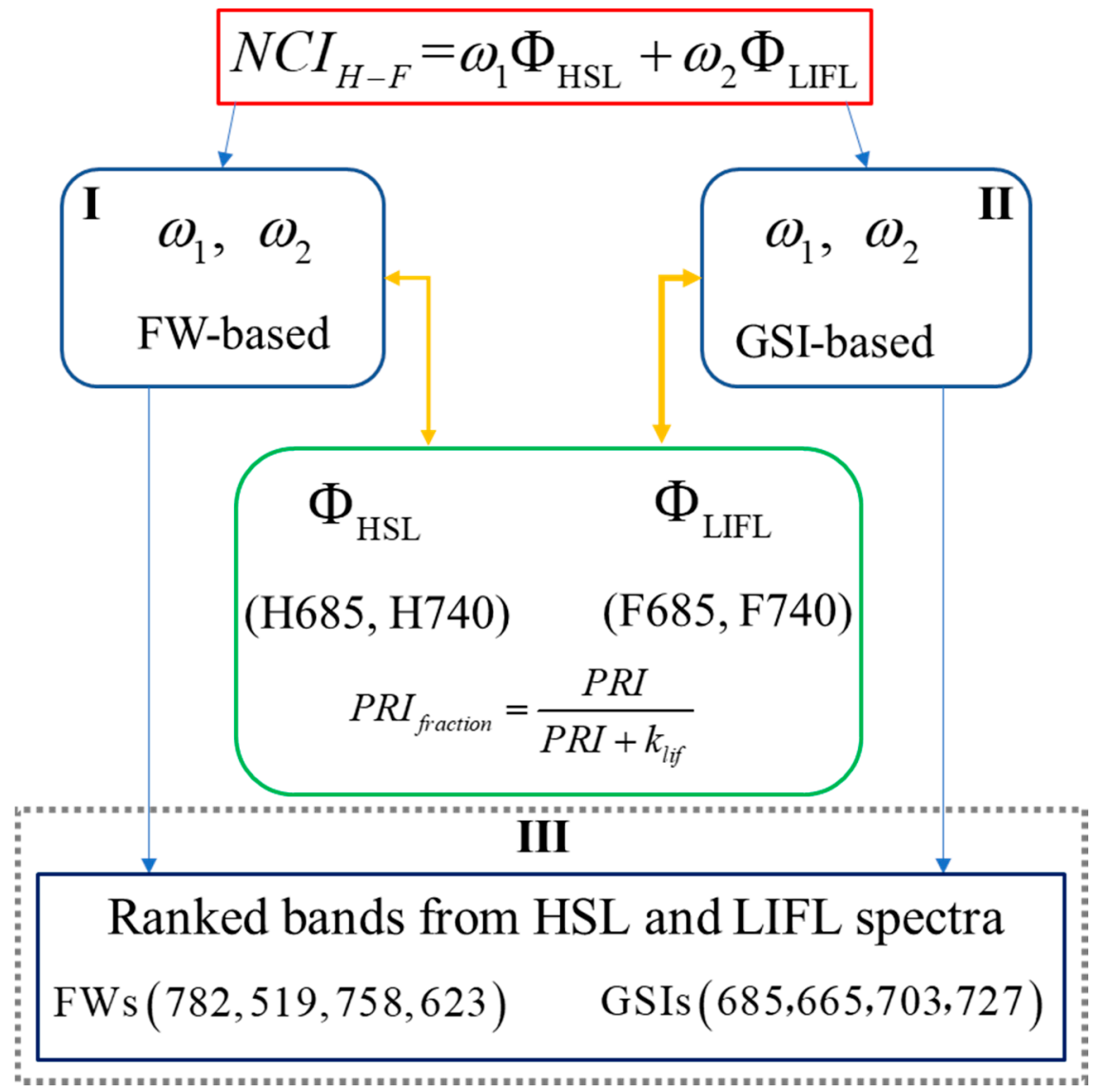

Figure 3. Overview of the analysis methods in this study.

\subsection{Two Methods for $\mathrm{NCI}_{\mathrm{H}-\mathrm{F}}$ Factor Calculation}

The $N C I_{H-F}$ values derived from HSL and LIFL data are linked in a linear form according to the contribution ratio of $S_{r}\left(\omega_{1}\right)$ and $S_{f}\left(\omega_{2}\right)$ to LNC, as determined with two methods described in Sections 3.2.1 and 3.2.2. The values of $\Phi_{\mathrm{HSL}}$ and $\Phi_{\mathrm{LIFL}}$ in Equation (1) may represent the intensity of $S_{r}$ and $S_{f}$ in a single band ( 685 or $740 \mathrm{~nm}$ ), and can represent the SIs derived from LiDAR data.

\subsubsection{Feature Weights for Each Spectral Band}

The FWs of each band represent the efficient indicators linking the spectra in wide-bands to biochemical contents. In this work, FWs were calculated on the basis of the divergence for each class divided according to vegetation species and biochemical contents. In the calculation process, a significant coefficient of band corresponding to class $j, \eta_{j}(\lambda)(j=1,2, \ldots, m)$, was ranked in descending order with Equation (3) according to band sensitivity to the different biochemistry parameters. Subsequently, the FWs for each band were calculated using Equation (2), where $P_{\text {re-ranked }}^{\lambda}$ was the band position in the sequence of $\eta_{j}(\lambda)$ in Equation (3),

$$
\begin{gathered}
F W_{s}(\lambda)=\frac{1}{n} \sum_{j=1}^{m}\left(P_{\text {re-ranked }}^{\lambda}\right) \\
\eta_{j}(\lambda)=\frac{1}{n} \sum_{i=1}^{n} \mu_{i}\left(E_{\lambda i}\right)^{2}(i=1,2, \ldots, n)
\end{gathered}
$$


where $n$ is the number of bands, $\mu_{i}$ represents a divergence ratio of the $i t h$ band to all bands, and $E_{\lambda i}$ denotes the elements of eigenvectors of the covariance matrix for each class.

\subsubsection{Global Sensitivity Indices for Each Spectral Band}

In this section, the sensitivity indices of parameters to the changes in total spectra in each band were noted as the new weights for constructing $\mathrm{NCI}_{H-F}$ for $\mathrm{LNC}$ estimation. Given that $\mathrm{k}$ variables affect the variation characteristics of LNC in a spectrum, the set of parameter variables was defined as $\mathrm{A}=\left[a_{1}, a_{2}, \ldots, a_{k}\right]$. For $\mathrm{A}=\left[a_{1}\right]$, only one variable was present, and $a_{i}=\overline{a_{i}}$, the variance of $R(\lambda)$ was $\operatorname{Var}\left[R(\lambda) \mid \overline{a_{i}}\right]$. Generally, the value of $\overline{a_{i}}$ was unpredictable. Hence, the variance was unavailable. However, the expectation for $R(\lambda)$ can be calculated according to all the possible values of $a_{i}$, which can be substituted with the variance, noted as $\mathrm{E}\left[R(\lambda) \mid a_{i}\right]$. Then, the sensitivity of the single variable $G S I_{i}^{s}$ to the reflection spectrum can be characterized using the following formula:

$$
G S I_{i}^{s}(\lambda)=\frac{\operatorname{Var}\left(\mathrm{E}\left[R \mid a_{i}\right]\right)}{\operatorname{Var}(R)} .
$$

This equation was used in a local sensitivity analysis called the first-order sensitivity index, which disregarded the influence of other parameters. In fact, a feature spectrum is not determined by a single variable but is the result of the interaction of many factors, and usually $\operatorname{GSI}_{i j}^{s}(\lambda) \geq \operatorname{GSI}_{i}^{s}(\lambda)+\operatorname{GSI}_{j}^{s}(\lambda)$. In this work, a total sensitivity index (Equation (5)) with multivariable was calculated by taking the spatial autocorrelation coefficient $\gamma(\lambda)$ as the input condition, and was used as the basis for the priority ranking of sensitive bands.

$$
\operatorname{GSI}_{k}^{s}(\lambda)=\frac{\operatorname{Var}\left(\mathrm{E}\left[R \mid \gamma\left(a_{1}, s_{2}, \ldots, a_{k}\right)\right]\right)}{\operatorname{Var}(R)}
$$

Each variable shows unique sensitivity in different bands, and even the spectral intensity in the same band depends on multiple parameters. This attribute is not only a powerful basis for constructing $N C I_{H-F}$ for LNC estimation, but also an essential analysis strategy for the inversion and extraction of specific biochemical parameters.

\subsection{Artificial Neural Networks for LNC Estimation}

In this section, an ANN with four training functions, namely, Levenberg-Marquardt Algorithm (trainlm), Bayesian regularization algorithm (trainbr), Quasi-Newton Algorithm (trainbfg), and one step secant algorithm (trainoss) were described, and then utilized for the prediction of rice LNC with the constructed $\mathrm{NCI}_{\mathrm{H}-\mathrm{F}}$ values.

The feed forward ANNs in this work consisted of three layers, namely input, hidden, and output, which were created, trained, and implemented in the Matlab 2014b environment. Four commonly used training functions were adopted respectively. Additionally, the ANN conditions were set as follows: minimum mean square error (MSE) of $10^{-3}$, minimum gradient of $10^{-6}$, and maximum iteration number (epochs) of 100. After the conditions were met, the ANNs iteration process was stopped. Other details about ANNs can be found in the work of Yegnanarayana [52] and the documents of software Matlab 2014b.

$$
y=f_{\text {non }}\left(\sum_{i=1}^{n} b_{i} X_{i}+c_{i}\right)
$$

The nonlinear activation function $f_{\text {non }}$ in Equation (6) was used in processing the iteration process. The function generated a y value as the predicted LNC, where $b_{i}$ is the network weight and $c_{i}$ is the bias, which were all adjusted along with the gradient-decreased MSE. 


\section{Results}

Figure 2 shows the spectra of $S_{r}$ and $S_{f}$ collected by HSL and LIFL systems under four different LNC levels, and the distribution of prior LNC-sensitive bands on the $S_{r}$ and $S_{f}$ curves. The features of $S_{r}$ and $S_{f}$ in special bands were closely related to the LNC values of rice, which could be correctly measured by these two LiDAR systems, whether there was a positive or negative relationship. Thus, these two LiDAR systems were reliable remote sensing tools for rice feature spectra measurement, regardless of $S_{r}$ or $S_{f}$ characteristics under different LNC levels. Moreover, prior bands selected with FWs and GSIs were discretely distributed onto the $S_{r}$ and $S_{f}$ curves and covered most LNC-sensitive bands. This finding indicated that the analysis of feature weight and the global sensitivity of numerous factors to the spectral intensity in each special band was powerful potential method for selecting preferentially sensitive bands for vegetation biochemical estimation, especially $\mathrm{N}$.

On the basis of a series of spectra of $S_{r}$ and $S_{f}$ collected by HSL and LIFL system, we constructed numerous combined SIs linked by FWs and GSIs for LNC estimation, and finally obtained some SIs with high $R^{2}$ (that $>0.7$ have been in bold in Table 1, Table 2, and Table 4) for LNC prediction models. Generally, the combined SIs performed well in rice LNC modeling in the specified bands, i.e., 685 and $740 \mathrm{~nm}$. Subsequently, we analyzed the ability of $N C I_{H-F}$ in four prior bands on LNC estimation (Section 4.3), and these ranked bands were selected according to FW and GSI values respectively.

Table 1. FW-based $N C I_{H-F}$ used for LNC estimation and its corresponding $R^{2}$ and RMSE for the year of 2014 and 2015 respectively.

\begin{tabular}{|c|c|c|c|c|c|c|c|c|}
\hline \multirow{2}{*}{$N C I_{H-F}$} & \multicolumn{2}{|c|}{ 2014-B } & \multicolumn{2}{|c|}{ 201402-H } & \multicolumn{2}{|c|}{ 2015-T } & \multicolumn{2}{|c|}{ Spectral Variables } \\
\hline & $R^{2}$ & RMSE & $R^{2}$ & RMSE & $R^{2}$ & RMSE & $\Phi_{\mathrm{HSL}}$ & $\Phi_{\text {LIFL }}$ \\
\hline$N C I_{H-F}$ 0_W & $0.74^{\mathrm{c}}$ & 0.28 & $0.70^{\mathrm{c}}$ & 0.45 & * & * & $\sum(H 685, H 740)$ & $\sum(F 685, F 740)$ \\
\hline$N C I_{H-F}$ 1_W & $0.72^{a}$ & 0.15 & $0.72^{c}$ & 0.32 & $0.61^{\mathrm{d}}$ & 0.28 & $\sum(H 685, H 740)$ & $\sum(F 685, F 740)$ \\
\hline $\mathrm{NCI}_{H-F} 2{ }_{-} \mathrm{W}$ & $0.51^{b}$ & 0.18 & $0.62^{c}$ & 0.30 & $0.79^{c}$ & 0.23 & H685 & F685 \\
\hline PRI $I_{\text {fraction_W }}$ & $0.57^{\mathrm{c}}$ & 0.32 & $0.74^{\mathrm{c}}$ & 0.23 & $0.70^{c}$ & 0.13 & / & F740 \\
\hline
\end{tabular}

Note: The training functions of ANN models include ${ }^{a}$ trainlm, ${ }^{b}$ trainbr, ${ }^{\mathrm{c}}$ trainbfg, and ${ }^{\mathrm{d}}$ trainoss, with the same marks in Table 2 and Table 4.

Table 2. GSI-based NCIH-F used for LNC estimation and its corresponding $R^{2}$ and RMSE for year of 2014 and 2015 respectively.

\begin{tabular}{|c|c|c|c|c|c|c|c|c|}
\hline \multirow{2}{*}{$N C I_{H-F}$} & \multicolumn{2}{|c|}{ 2014-B } & \multicolumn{2}{|c|}{ 201402-H } & \multicolumn{2}{|c|}{ 2015-T } & \multicolumn{2}{|c|}{ Spectral Variables } \\
\hline & $R^{2}$ & RMSE & $R^{2}$ & RMSE & $R^{2}$ & RMSE & $\Phi_{\mathrm{HSL}}$ & $\Phi_{\text {LIFL }}$ \\
\hline$N C I_{H-F} 1 \_S$ & $0.76^{c}$ & 0.31 & $0.82^{d}$ & 0.27 & $0.70^{c}$ & 0.2 & $\sum(H 685, H 740)$ & $\sum(F 685, F 740)$ \\
\hline$N_{C I} I_{H-F} 2 \_S$ & $0.75^{c} / 0.71^{d}$ & $0.18 / 0.29$ & $0.63^{\mathrm{d}}$ & 0.35 & $0.45^{c}$ & 0.36 & $\mathrm{H} 740$ & F740 \\
\hline PRI fraction_S & $0.58^{a}$ & 0.35 & $0.67^{\mathrm{d}}$ & 0.26 & $0.74^{b}$ & 0.16 & I & F740 \\
\hline
\end{tabular}

\subsection{LNC Estimation Using FW-Based $N C I_{H-F}$}

On the basis of the construction form of $N C I_{H-F}$ in Equation (1), four FW-based $N C I_{H-F}$ with high $R^{2}$ values were obtained during rice LNC estimation (Table 1$)$. The superscripts ( $a, b, c$ and d) of each $R^{2}$ in Table 1 indicates the four training functions of ANN models used in examining the relationship between $\mathrm{LNC}$ and $\mathrm{NCI}_{\mathrm{H}-\mathrm{F}}$. The obtained $\mathrm{NCI}_{\mathrm{H}-\mathrm{F}}$ can be classified into two types, namely, the sum of HSL and LIFL variables in two specified bands (685 and $740 \mathrm{~nm}$, marked with $N_{C} I_{H-F}{ }_{-} W$ in Table 1), that is, there are four variables (H685, H740, F685 and F740). Another type is the modified photochemical reflectance index (PRI), called PRI fraction (Equation (7)) which is also presented in Table 1. Similar to the combined form of $N C I_{H-F}$, the bands used in $P R I_{\text {fraction, }}$, including 531, 570 and $740 \mathrm{~nm}$, were also replaced with $\mathrm{FWs}^{*} \Phi$, or GSIs $\Phi^{*}$ in the subsequent analysis. PRI is commonly used as an 
indicator of vegetation photosynthesis process. In this study, the item $k_{\text {lif }}$ in Equation (7) was replaced with F740, which is expressed Equation (9) as follows:

$$
\begin{gathered}
P R I_{\text {fraction }}=\frac{P R I}{P R I+k_{\text {lif }}} \\
P R I=\frac{I_{531}-I_{570}}{I_{531}+I_{570}} \\
P R I_{\text {fraction }}=\frac{P R I}{P R I+F_{740}}
\end{gathered}
$$

For $N C I_{H-F} 0 \_W$ in Table 1 , we set a constant weight of 0.5 , whereas $\omega_{1}=\omega_{2}=0.5$ for each spectral variable, and obtained an $R^{2}$ of 0.74 in the booting stage and a $R^{2}$ of 0.7 in the heading stage of 2014 . Replacing $\omega_{1}$ and $\omega_{2}$ with the corresponding FWs for 685 and $740 \mathrm{~nm}$ alternatively $\left(N C I_{H-F} 1_{-} W\right)$, the model results were improved by more than 0.8 and 0.72 in 2014 respectively. In 2015, the $N C I_{H-F}$ with a constant contribution weight of 0.5 , had no outstanding performance in LNC estimation. By replacing the constant weights with their FWs, we could obtain an $R^{2}$ of 0.61 for $N C I_{H-F} 1 \_W$. For $N C I_{H-F} 2$ _W, the spectral variables of $N C I_{H-F}$ were single band $(\mathrm{H} 685, \mathrm{~F} 685)$, which were different from those of $N C I_{H-F} 1 \_W$. Table 1 shows that the $R^{2}$ of $N C I_{H-F} 1 \_W$ model can be more than 0.79 for 2015 , while is less than 0.7 for both stages of 2014 .

\subsection{LNC Estimation Using GSI-Based $N C I_{H-F}$}

As shown in Section 4.1, the same kinds of $N C I_{H-F}$ obtained $R^{2}$ values of $>0.7$ in this section. The difference with FW-based $N C I_{H-F}$ was that the spectral variables are connected with GSIs, and some items used to construct $\mathrm{NCI}_{\mathrm{H}-\mathrm{F}}$ in the same form had changed. For example, for $N C I_{H-F} 2 \_\mathrm{S}$ the spectral variable was (H740, F740), and not the (H685, F685) in $N C I_{H-F} 2 \_W$. The $N C I_{H-F} 2$ S model for LNC estimation performed well in 2014-B, but obtained an unsatisfactory result in 2014-H, and even a bad performance in 2015-T. When the GSI-based $N C I_{H-F}$ in four spectral variables was used, the $N C I_{H-F} 1 \_S$ was available in 2014 and 2015 data, obtaining a mean $R^{2}$ of 0.76 (Table 2). However, for

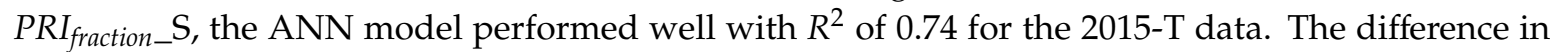
performance can be found in Section 4.1, which shows a relatively good results in 2014-H and 2015-T. Thus, the spectra in different years can be a noteworthy issue in the LNC estimation of rice.

The PRI has been demonstrated to be a robust spectral index that is closely related to the vegetation photosynthesis process in leaf and canopy scales [2]. PRI has the same construction form as NDVI, which is calculated in 531 and $570 \mathrm{~nm}$ (Equation (8)). As well, PRI had been proved the available ability on LNC estimation with different training functions of ANNs in this study. In comparison with $P R I$, we found that the $P R I_{\text {fraction }}$ with FW- and GSI-based weights could be a more effective index for LNC estimation in rice. For example, the total mean $R^{2}$ of $P R I$ was 0.68 for the 2015 data (Figure 4); this value was slightly lower than the $P R I_{\text {fraction }}$ values represented in Tables 1 and 2 . Thus, the FW- and GSI-based weights could be efficiently used in improving the performance of PRI in LNC estimation on the basis of $S_{r}-S_{f}$ features obtained with HSL and LIFL systems. Notably, the mean $R^{2}$ of $P R I$ was 0.69 in both stages of 2014, and these values were higher than the PRI fraction modified based on the FWs and GSIs in Tables 1 and 2. These results indicated that the growth stages and years of rice served as relatively sensitive factor which affected the model performance of combined SIs in LNC estimation. 


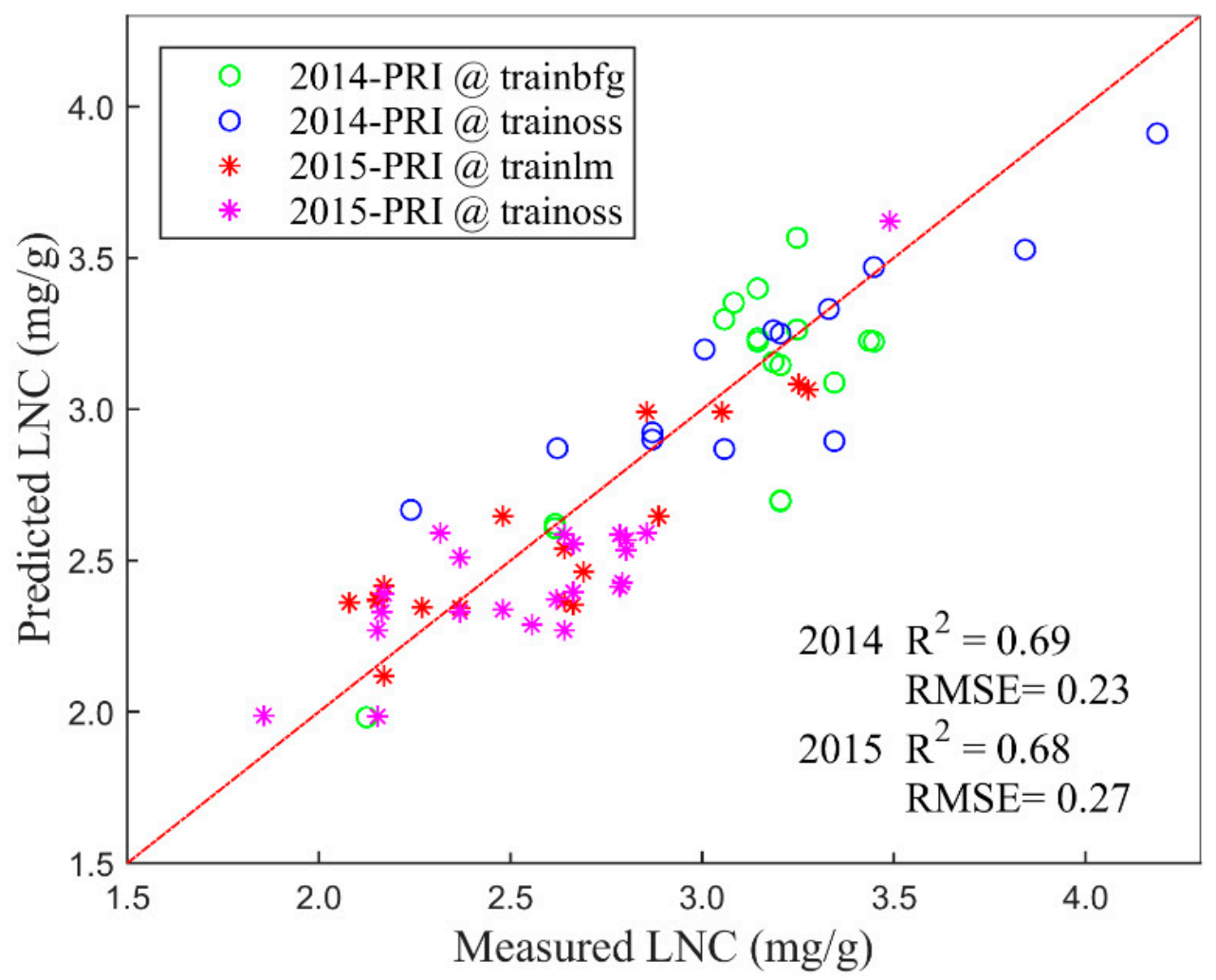

Figure 4. Performance of PRI in LNC estimation, the $R^{2}$ and RMSE are the mean values of 2014- and 2015-year data.

\section{3. $N C I_{H-F}$ in Ranked Bands for LNC Estimation}

In this section, the bands used to construct $N C I_{H-F}$ were selected preferentially based on the FW and GSI values. Then, the first four prior bands were selected as the spectral variables for the calculation of $\mathrm{NCI}_{\mathrm{H}-\mathrm{F}}$, and modeling of rice LNC with the ANN method. These prior bands are the LNC-sensitive characteristics to rice LNC, and they are discretely distributed onto some critical positions of HSL and LIFL spectra (Figure 2). Concretely, the positive relationship between $\mathrm{N}$ level and $S_{r}$ intensity can be changed to a negative relationship in approximately $700 \mathrm{~nm}$. Alternatively, for $S_{f}$, the double-peak spectra in 650-750 nm regularly increased along with the $\mathrm{N}$ level.

Based on the positions of these selected bands, four FW-based prior variables for $S_{r}$ were almost distributed in the near-infrared band. These variables were significantly important to the GSV because of the reflectance and absorption characteristics of pigments in vegetation leaf. In $S_{f}$ curve, FW-based prior bands were distributed discretely over the whole interest range of 450-800 nm (Figure 2b). For the prior bands selected by GSI values, two bands located in the "red-edge" position of $S_{r}$ curve, while all of them located in the bands centered about the double-peak characteristics in $S_{f}$ curve.

With these selected bands, $N C I_{H-F}$ was calculated and then unitized in estimating LNC for the 2014- and 2015-year data based on ANNs method. The results could be found in Figure 5, which showed the optimal $R^{2}$ among these band-ranked $N C I_{H-F}$. In comparison with the use of specified bands in the above section, the $N C I_{H-F}$ with ranked bands generally had an acceptable modeling accuracy for the 2014 and 2015 data, whereas for GSI-based $N C I_{H-F}$ the $R^{2}$ was less than 0.7 (Figure 5b). 

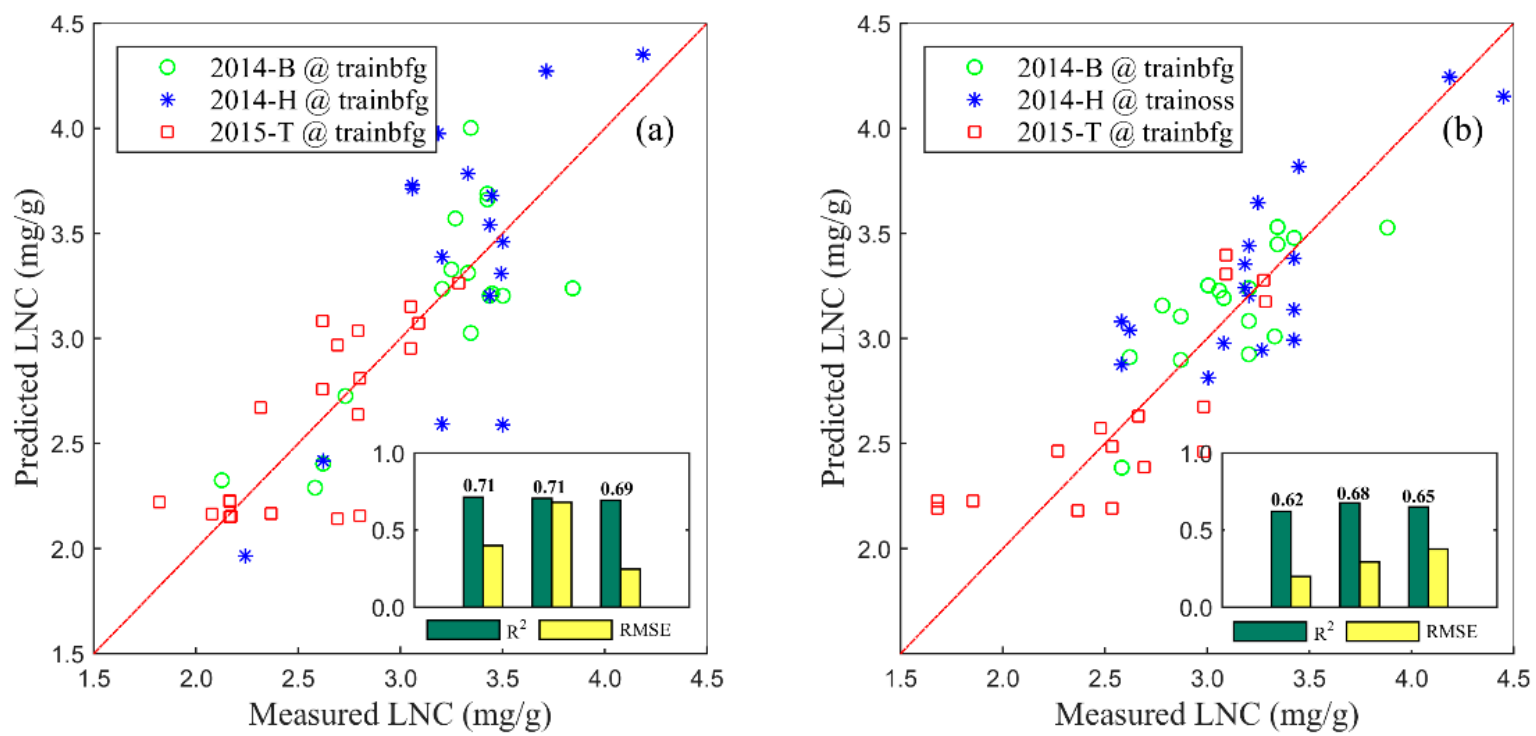

Figure 5. Estimation results of LNC using ANN with different training functions in 2015. Subgraph (a) shows the predicted versus measured LNC with FW-based $N C I_{H-F}$ in four prior bands; (b) is that using GSIs. Histograms show the corresponding $R^{2}$ and RMSE values for 2014-B, 2014-H and 2015-T respectively.

Linking factors $\left(\omega_{1}\right.$ and $\left.\omega_{2}\right)$ for $N C I_{H-F}$ in Equation (1) were listed in Table 3, in which the sum variables $(\mathrm{H} 685 \mathrm{H} 740)$ and (F685 F740) for $N C I_{H-F}$ 1_W and _S had the comparative contribution to $N C I_{H-F}$ (approximately 0.5 ). However, for FW-based $N C I_{H-F}$, the values of $\omega_{1}$ and $\omega_{2}$ for single variable, such as $\mathrm{H} 685$ and F685, were 0.27 and 0.73 respectively, indicating that the $S_{r}$ features from HSL data had a weaker contribution to LNC than that using $S_{f}$ from the LIFL data. For GSI-based $N C I_{H-F}$, namely $\mathrm{NCI}_{\mathrm{H}-\mathrm{F}} 2 \mathrm{~S}$ with variables of $\mathrm{H740}$ and F740, had the near factor values $\left(\omega_{1}=0.50\right.$ and $\left.\omega_{2}=0.50\right)$. For the $P R I_{\text {fraction }}$, the variable in the denominator was replaced by F740, with FW and GSI values as the contribution ratios $\omega_{1}$ and $\omega_{1}$, and being less than 0.4 ( 0.35 and 0.24 respectively).

Table 3. Values of $\omega_{1}$ and $\omega_{2}$ in Equation (1) calculated with FWs and GSIs for four spectral variables, namely (H685 H740) and (F685 F740).

\begin{tabular}{|c|c|c|c|c|c|}
\hline \multicolumn{2}{|c|}{$N C I_{H-F}$} & $\Phi_{\mathrm{HSL}}$ & $\omega_{1}$ & $\Phi_{\text {LIFL }}$ & $\omega_{2}$ \\
\hline \multirow{4}{*}{ FW-based } & $N C I_{H-F} 0 \_W$ & $\sum(F 685, F 740)$ & 0.50 & $\sum(F 685, F 740)$ & 0.50 \\
\hline & $\mathrm{NCI}_{H-F}$ 1_W & $\bar{\Sigma}(F 685, F 740)$ & 0.52 & $\bar{\Sigma}(F 685, F 740)$ & 0.48 \\
\hline & $N C I_{H-F} 2 \_\mathrm{W}$ & H685 & 0.27 & F685 & 0.73 \\
\hline & PRI fraction_W & $\&$ & l & F740 & 0.35 \\
\hline \multirow{3}{*}{ GSI-based } & $N C I_{H-F} 1 \_S$ & $\sum(F 685, F 740)$ & 0.52 & $\sum(F 685, F 740)$ & 0.48 \\
\hline & $N C I_{H-F} 2 \_S$ & $\mathrm{H} 740$ & 0.50 & F740 & 0.50 \\
\hline & PRI fraction_S & $\&$ & / & F740 & 0.24 \\
\hline
\end{tabular}

Note: \& The $\Phi_{\text {HSL }}$ variable for $P R I_{\text {fraction }}$ is related with the $S r$ features in band of 531 and $570 \mathrm{~nm}$, and the values of $\omega_{2}$ are respectively calculated with the FWs and GSIs in bands of 531 and $570 \mathrm{~nm}$ following Equations (7) and (8).

\section{Discussion}

\subsection{Comparison with Previously Published Methods}

Both $S_{r}$ and $S_{f}$ features are the important indicators for GSV monitoring. Thus, we attempted to find an effective way to combine these two spectral properties together for LNC modeling. The first thing we could conceive was to construct a common SI based on the HSL and LIFL data, which is sensitive to rice LNC. Vegetation LNC is thought to be codetermined by $S_{r}-S_{f}$ characteristics, and the values of $\omega_{1}$ and $\omega_{2}$ can be considered as their corresponding contribution ratios to LNC. Some 
combined indices derived from HSL and LIFL data had been proposed in some previous works. Shi et al. [40] developed a kind of combined index with the similar form as NDVI by combining HSL and LIFL spectral variables, called $N(\mathrm{H} 685, \mathrm{~F} 685)$ and $N(\mathrm{H} 740, \mathrm{~F} 740)$ in Equation (10). However, these combined indices performed poorly, and even had a weaker ability for LNC modeling than the ratio indices obtained by using HSL or LIFL spectra separately. In this work, we linked the HSL and LIFL variables to rice LNC as expressed in a form of Equation (1), and named as $N C I_{H-F}$, which was constructed by significant factor, such as FWs and GSIs for each band. Accordingly, we improved the estimation results efficiently. In addition, we found that adding more characteristics entered as the model input did not necessarily improve the results. Conversely, the combined SIs with only two spectral variables showed the same good model $R^{2}$, such as the $N C I_{H-F} 2 \_S$ in Table 2, and HL-NormIndex_W and_S in Table 4. Hence, multiplying the bands with their corresponding FWs or GSIs may efficiently combine $S_{r}$ and $S_{f}$ together for LNC estimation, and the ability of SIs for LNC estimation relies mostly on the combination forms of spectral variables.

$$
\begin{aligned}
& N(H 685, F 585)=\frac{H 685-F 685}{H 685+F 685} \\
& N(H 740, F 740)=\frac{H 740-F 740}{H 740+F 740}
\end{aligned}
$$

Table 4. Comparison of estimated LNC results between the published combined indices in Du et al. and the FW/GSI-based $N_{C I}$ in the same form as NDVI based on the data from 2014- and 2015-year. (SI of $N(\mathrm{H} 685, \mathrm{~F} 685)$ and $N(\mathrm{H} 740, \mathrm{F740})$ can be calculated with Equations (10) and (11), respectively).

\begin{tabular}{lllllll}
\hline \multirow{2}{*}{ Combined Index } & \multicolumn{2}{c}{ 2014-B } & \multicolumn{2}{c}{ 201402-H } & \multicolumn{2}{c}{ 2015-T } \\
\cline { 2 - 7 } & $\boldsymbol{R}^{\mathbf{2}}$ & RMSE & $\boldsymbol{R}^{\mathbf{2}}$ & $\mathbf{R M S E}^{\mathbf{2}}$ & $\boldsymbol{R}^{\mathbf{2}}$ & RMSE \\
\hline N(H685, F685) & 0.408 & 0.479 & 0.698 & 0.269 & 0.479 & 0.499 \\
N(H740,F740) & 0.488 & 0.579 & 0.597 & 0.358 & 0.498 & 0.491 \\
HL-NormIndex_W & $\mathbf{0 . 7 4}^{\text {a }} \mathbf{0 . 7 1}^{\mathbf{d}}$ & $0.11 / 0.16$ & $\mathbf{0 . 8 1}^{\mathbf{b}}$ & 0.15 & $\mathbf{0 . 7 2}^{\mathbf{c}}$ & 0.14 \\
HL-NormIndex_S & $\mathbf{0 . 7 3}^{\mathbf{c}}$ & 0.22 & $\mathbf{0 . 7 0}^{\mathbf{d}}$ & 0.23 & $\mathbf{0 . 8 2}^{\text {c }}$ & 0.16 \\
\hline
\end{tabular}

Moreover, with the purpose of supporting the above conclusion and further improving the SIs performance on LNC estimation [38], we replaced the spectral variables in Equation (9), including H685, F685, H740 and F740, by FWs and GSIs multiplied with the corresponding bands, and then conducted LNC modeling with these modified SIs. Table 4 showed that the model performance was improved, and some $R^{2}$ values distinctly reached 0.82 (HL-NormIndex_W and_S) while with a lower RMSE. Thus, the FW- and GSI-based methods in this work may be used to efficiently construct combined SIs for LNC estimation and improve the model performance significantly.

\subsection{Prior Bands Selection}

In Figure 5, the FW-based combined SIs performed better in linking $N C I_{H-F}$ to rice LNC than that SIs using GSI values. The selected bands from the HSL and LIFL spectrum in Figure 2 can also explain this result. The prior bands ranked based on FWs were regularly located in the major $S_{r}$ range, thereby covering more features related to LNC, such as the "red-edge" position, and Chl absorption area. Comparatively, the GSI-based $\mathrm{NCI}_{H-F}$ in this work was usually calculated with the bands in the red-range but lacked some characteristics, which might decrease its universality in estimating LNC or other biochemicals. Meanwhile, the prior bands selected with mathematics (FWs) or physical model (GSIs) cannot consider all these variables from different experimental and environmental situations. However, the spectral variables in 685 and $740 \mathrm{~nm}$ are the important features for GSV, which has been determined by many researchers [53]. Thus, the results of $N C I_{H-F}$ in specified bands obtaining a better model performance for LNC estimation than that in four prior bands can be reasonable. 
The spectra collected with optical sensors, even for the active LiDAR used in this work, are the direct indicators for $\mathrm{Chl}$ contents in vegetation leaf, and these indicators can be used as the basis of LNC monitoring by remote sensing method. However, the LNC and Chl of vegetation are not same parameters after all, even though they are closely related to each other. In this work, FWs for each band were calculated based on a mass of modeled and collected spectra [54,55] and LNC measurement in the laboratory, whereas the GSIs were analyzed based on the fluorescence model with inputs that do not contain LNC [56]. This may contribute to the prior bands being selected with GSIs are not Chl-sensitive for LNC. Thus, GSI-based bands do not cover the total characteristics for LNC in HSL and LIFL spectra in Figure 2, indicating that the GSI-based $N C I_{H-F}$ obtained a lower $R^{2}$ than that using FWs.

\subsection{Limitation and Future Research}

In this study, rice LNC was successfully estimated by $\mathrm{NCI}_{H-F}$. However, the model should be recalibrated when applied to other vegetations or even to rice grown under different environmental conditions. Moreover, the ANN model used in this study greatly depended on the selection of training and validation dataset, which would change during LNC modeling. Thus, a universal and dataset-independent method should be determined for the combination of the spectra of $S_{r}$ and $S_{f}$ for LNC or other biochemical estimation. This study attempted to solve this problem by forming a novel SI which linked $S_{r}$ and $S_{f}$ in a linear equation with two factors, namely, FWs and GSIs. However, we should admit that the FW- and GSI-based $N C I_{H-F}$ was conducted based on the spectra from two separate datasets, which might contribute errors to the ANN models of LNC estimation because of the non-uniform dataset.

Furthermore, the FW and GSI values of each band represented quite a contribution ratio of $S_{r}$ and $S_{f}$ to the LNC, although a certain physical significance was observed in the linear form $N C I_{H-F}$ to some extent. The two factors were calculated using a statistical method, especially for FWs, which greatly depended on sample spectra. In a recent study, the biochemical estimation of vegetation was conducted based on the radiative transfer models (RTMs), including the SCOPE model (Soil Canopy Observation, Photochemistry and Energy fluxes) proposed by Christiaan et al. $[57,58]$ and one of the separated components of SCOPE, namely, the Fluspect-B model [59]. Unlike the PROSPECT model with leaf reflectance and transmittance spectra [55] and the FluorMODleaf model with leaf $S_{f}$ [60], both SCOPE and Fluspect-B can simulate the total spectra of $S_{r}$ and $S_{f}$ simultaneously, rather than being univocal for generating a special spectrum without considering all feature spectra together to estimate the vegetation biochemicals [61]. Based on the uniform spectra of $S_{r}$ and $S_{f}$ generated by SCOPE or Fluspect-B model, the FWs and GSIs for each band can be calculated, which might further improve the performance and universality of the ANN model in rice LNC estimation, and even for some other biochemicals, such as moisture, dry matter, and so on, which are important indicators for the GSV, as well as for land coverage and change detection, which are critically significant for the analysis of the carbon-nitrogen cycle [62], near surface atmosphere temperature [63-65], and dynamics variation in permafrost region $[66,67]$ among other fields.

\section{Conclusions}

This study proposed a combined spectral index, namely, the $N C I_{H-F}$ for $L N C$ estimation. The $N C I_{H-F}$ was constructed in a linear combination form linked spectra of $S_{r}$ and $S_{f}$ collected with HSL and LIFL systems to rice LNC based on two factors, namely FWs and GSIs for each feature band. By using an additive SI in two specific bands (685 and $740 \mathrm{~nm}$ ), the $N C I_{H-F}$ values in this work could be utilized to estimate rice LNC accurately under multi-year rice samples. Thus, the $N C I_{H-F}$ is the available and reliable combined form for combining HSL and LIFL spectral characteristics for rice LNC estimation. Simultaneously, the modified $P R I$, called $P R I_{\text {fraction }}$, demonstrated a satisfactory performance in rice LNC estimation by replacing some items with $S_{f}$ variables, multiplying corresponding FWs and GSIs in $740 \mathrm{~nm}$. These results showed that FWs and GSIs could indicate the main contribution of each band to LNC, which were essential and valuable parameters for constructing novel SIs for LNC estimation 
of rice. Moreover, the FW and GSI values for each feature band were multiplied to some previous combined SIs, for instance, $N(\mathrm{H} 685$, F685) and N(H740, F740), and improved the model performance of LNC estimation significantly. This result further supported the above conclusion that FW- and GSI-based $N C I_{H-F}$ is efficient in remotely sensing rice LNC, and combining $S_{r}$ and $S_{f}$ features in a linear form is a reliable way to improve the model performance in LNC estimation based on the HSL and LIFL spectra.

Author Contributions: Conceptualization, L.D., W.G. and B.C. (Bowen Chen); methodology, L.D. and J.S.; software, L.D. and J.Y.; validation, B.C. (Biwu Chen) and S.S. (Shuo Shi); formal analysis, L.D. and S.S. (Shalei Song); writing—original draft preparation, L.D.; writing—review and editing, L.D. and S.S. (Shalei Song). All authors have read and agreed to the published version of the manuscript.

Funding: This research was funded by National Key Research and Development Program of China, grant number 2018YFB0504500; National Natural Science Foundation of China, grant number 41801268; Natural Science Foundation of Hubei Province, grant number 2018CFB272; Fundamental Research Funds for the Central Universities, China University of Geosciences (Wuhan), grant number CUG170662.

Acknowledgments: The authors wish to thank the College of Plant Science \& Technology of Huazhong Agricultural University for providing the experimental samples and Wuhan Academy of Agricultural Science \& Technology for providing the LNC of samples.

Conflicts of Interest: The authors declare no conflict of interest.

\section{References}

1. Clevers, J.G.; Gitelson, A.A. Remote estimation of crop and grass chlorophyll and nitrogen content using red-edge bands on Sentinel-2 and -3. Int. J. Appl. Earth Obs. Geoinf. 2013, 23, 344-351. [CrossRef]

2. Kergoat, L.; Lafont, S.; Arneth, A.; Le Dantec, V.; Saugier, B. Nitrogen controls plant canopy light-use efficiency in temperate and boreal ecosystems. J. Geophys. Res. Biogeosci. 2008, 113, 1-19. [CrossRef]

3. Ikawa, H.; Chen, C.P.; Sikma, M.; Yoshimoto, M.; Sakai, H.; Tokida, T.; Usui, Y.; Nakamura, H.; Ono, K.; Maruyama, A.; et al. Increasing canopy photosynthesis in rice can be achieved without a large increase in water use-A model based on free-air $\mathrm{CO}_{2}$ enrichment. Glob. Chang. Biol. 2018, 24, 1321-1341. [CrossRef] [PubMed]

4. Dechant, B.; Cuntz, M.; Vohland, M.; Schulz, E.; Doktor, D. Estimation of photosynthesis traits from leaf reflectance spectra: Correlation to nitrogen content as the dominant mechanism. Remote Sens. Environ. 2017, 196, 279-292. [CrossRef]

5. Diacono, M.; Rubino, P.; Montemurro, F. Precision nitrogen management of wheat. A review. Agron. Sustain. Dev. 2012, 33, 219-241. [CrossRef]

6. Zhang, N.; Wang, M.; Wang, N. Precision agriculture-A worldwide overview. Comput. Electr. Agric. 2002, 36, 113-132. [CrossRef]

7. Schlemmer, M.; Gitelson, A.; Schepers, J.; Ferguson, R.; Peng, Y.; Shanahan, J.; Rundquist, D. Remote estimation of nitrogen and chlorophyll contents in maize at leaf and canopy levels. Int. J. Appl. Earth Obs. Geoinf. 2013, 25, 47-54. [CrossRef]

8. Delegido, J.; Pasqualotto, N.; van Wittenberghe, S.; Verrelst, J.; Rivera, J.P.; Moreno, J. Retrieval of canopy water content of different crop types with two new hyperspectral indices: Water Absorption Area Index and Depth Water Index. Int. J. Appl. Earth Obs. Geoinf. 2018, 67, 69-78.

9. Wang, C.; Nie, S.; Xi, X.; Luo, S.; Sun, X. Estimating the biomass of maize with hyperspectral and LiDAR data. Remote Sens. 2016, 9, 11. [CrossRef]

10. Yi, Q.X.; Huang, J.F.; Wang, F.M.; Wang, X.Z.; Zhan, Y. Monitoring rice nitrogen status using hyperspectral reflectance and artificial neural network. Environ. Sci. Tech. 2007, 41, 6770-6775. [CrossRef]

11. Knyazikhin, Y.; Schull, M.A.; Stenberg, P.; Mõttus, M.; Rautiainen, M.; Yang, Y.; Marshak, A.; Carmona, P.L.; Kaufmann, R.K.; Lewis, P.; et al. Hyperspectral remote sensing of foliar nitrogen content. Proc. Natl. Acad. Sci. USA 2013, 110, E185-E192. [CrossRef] [PubMed]

12. Jones, H.G.; Vaughan, R.A. Remote Sensing of Vegetation: Principles, Techniques, and Applications; Oxford University Press: Oxford, UK, 2010; p. 134. 
13. Li, F.; Mistele, B.; Hu, Y.; Chen, X.; Schmidhalter, U. Reflectance estimation of canopy nitrogen content in winter wheat using optimised hyperspectral spectral indices and partial least squares regression. Eur. J. Agron. 2014, 52, 198-209. [CrossRef]

14. Johnson, L.F. Nitrogen influence on fresh-leaf NIR spectra. Remote Sens. Environ. 2001, 78, 314-320. [CrossRef]

15. Curran, P.J.; Dungan, J.L.; Peterson, D.L. Estimating the foliar biochemical concentration of leaves with reflectance spectrometry: Testing the Kokaly and Clark methodologies. Remote Sens. Environ. 2001, 76, 349-359. [CrossRef]

16. Portz, G.; Molin, J.; Jasper, J. Active crop sensor to detect variability of nitrogen supply and biomass on sugarcane fields. Precis. Agric. 2012, 13, 33-44. [CrossRef]

17. Gong, P.; Pu, R.; Heald, R. Analysis of in situ hyperspectral data for nutrient estimation of giant sequoia. Int. J. Remote Sens. 2002, 23, 1827-1850. [CrossRef]

18. Li, F.; Miao, Y.; Hennig, S.D.; Gnyp, M.L.; Chen, X.; Jia, L.; Bareth, G. Eevaluating hyperspectral vegetation indices for estimating nitrogen concentration of winter wheat at different growth stages. Precis. Agric. 2010, 11, 335-357. [CrossRef]

19. Pengfei, C.; Jihua, W.; Wenjiang, H.; Baoguo, L. Research of new vegetation index for estimating crop canopy biomass. Spectrosc. Spectr. Anal. 2010, 2, 512-517.

20. Tian, Y.C.; Gu, K.J.; Chu, X.; Yao, X.; Cao, W.X.; Zhu, Y. Comparison of different hyperspectral vegetation indices for canopy leaf nitrogen concentration estimation in rice. Plant Soil 2014, 376, 193-209. [CrossRef]

21. Du, L.; Wei, G.; Shuo, S.; Jian, Y.; Jia, S.; Bo, Z.; Shalei, S. Estimation of rice leaf nitrogen contents based on hyperspectral LIDAR. Int. J. Appl. Earth Obs. Geoinf. 2016, 44, 136-143. [CrossRef]

22. Liu, L.; Guan, L.; Liu, X. Directly estimating diurnal changes in GPP for C3 and C4 crops using far-red sun-induced chlorophyll fluorescence. Agric. For. Meteorol. 2017, 232, 1-9. [CrossRef]

23. Grace, J.; Nichol, C.; Disney, M.; Lewis, P.; Quaife, T.; Bowyer, P. Can we measure terrestrial photosynthesis from space directly, using spectral reflectance and fluorescence? Glob. Chang. Biol. 2010, 13, 1484-1497. [CrossRef]

24. Živčák, M.; Olšovská, K.; Slamka, P.; Galambošová, J.; Rataj, V.; Shao, H.; Brestič, M. Application of chlorophyll fluorescence performance indices to assess the wheat photosynthetic functions influenced by nitrogen deficiency. Plant Soil Environ. 2014, 60, 210-215. [CrossRef]

25. Apostol, S.; Viau, A.A.; Tremblay, N. A comparison of multiwavelength laser-induced fluorescence parameters for the remote sensing of nitrogen stress in field-cultivated corn. Can. J. Remote Sens. 2007, 33, 150-161. [CrossRef]

26. Janušauskaite, D.; Feiziene, D. Chlorophyll fluorescence characteristics throughout spring triticale development stages as affected by fertilization. Acta Agric. Scand. Sect. B-Soil Plant Sci. 2012, 62, 7-15.

27. Günther, K.; Dahn, H.-G.; Lüdeker, W. Remote sensing vegetation status by laser-induced fluorescence. Remote Sens. Environ. 1994, 47, 10-17. [CrossRef]

28. Subhash, N.; Mohanan, C. Laser-induced red chlorophyll fluorescence signatures as nutrient stress indicator in rice plants. Remote Sens. Environ. 1994, 47, 45-50. [CrossRef]

29. Sun, Y.; Guo, P.; Zhao, J.; Yu, Z. Effect of nitrogen application rate on flag leaf chlorophyll fluorescence characteristics and yield in wheat under integration of water and fertilizer. J. Triticeae Crop. 2018, 38, 988-994.

30. Yang, Y.; Wang, X.; Li, C.; Zhao, B.; Bai, R. Detection of pepper leaves nitrogen contents in greenhouse based on chlorophyll fluorescence image. J. Hunan Agric. Univ. (Nat. Sci.) 2017, 43, 108-111.

31. Yang, J.; Shi, S.; Gong, W.; Du, L.; Ma, Y.Y.; Zhu, B.; Song, S.L. Application of fluorescence spectrum to precisely inverse paddy rice nitrogen content. Plant Soil Environ. 2015, 61, 182-188. [CrossRef]

32. Jasper, J.; Reusch, S.; Link, A. Active sensing of the N status of wheat using optimized wavelength combination: Impact of seed rate, variety and growth stage, in Precision Agriculture'09: Papers. In Proceedings of the the 7th European Conference on Precision Agriculture, Wageningen, The Netherlands, 6-8 July 2009; Volume 2009, p. 923.

33. Chen, P.; Haboudane, D.; Tremblay, N.; Wang, J.; Vigneault, P.; Li, B. New spectral indicator assessing the efficiency of crop nitrogen treatment in corn and wheat. Remote Sens. Environ. 2010, 114, 1987-1997. [CrossRef]

34. Chappelle, E.W.; Wood, F.M.; McMurtrey, J.E.; Newcomb, W.W. Laser-induced fluorescence of green plants. 1: A technique for the remote detection of plant stress and species differentiation. Appl. Opt. 1984, 23, 134-138. [CrossRef] [PubMed] 
35. Zarco-Tejada, P.J.; Miller, J.R.; Mohammed, G.H.; Noland, T.L. Chlorophyll fluorescence effects on vegetation apparent reflectance: I. Leaf-level measurements and model simulation. Remote Sens. Environ. 2000, 74, 582-595. [CrossRef]

36. Zarco-Tejada, P.J.; Miller, J.R.; Mohammed, G.H.; Noland, T.L.; Sampson, P.H. Chlorophyll fluorescence effects on vegetation apparent reflectance: II. Laboratory and airborne canopy-level measurements with hyperspectral data. Remote Sens. Environ. 2000, 74, 596-608. [CrossRef]

37. Du, S.S.L.; Jian, Y.; Jia, S.; Wei, G. Using different regression methods to estimate leaf nitrogen content in rice by fusing hyperspectral LiDAR data and laser-induced chlorophyll fluorescence data. Remote Sens. 2016, 8, 526. [CrossRef]

38. Jian, Y.; Du, L.; Jia, S.; Zhengbing, Z.; Biwu, C.; Shi, S.; Wei, G.; Shalei, S. Estimating the leaf nitrogen content of paddy rice by using the combined reflectance and laser-induced fluorescence spectra. Opt. Express 2016, 24, 19354-19365.

39. Weersink, R.; Patterson, M.S.; Diamond, K.; Silver, S.; Padgett, N. Noninvasive measurement of fluorophore concentration in turbid media with a simple fluorescence/reflectance ratio technique. Appl. Opt. 2001, 40, 6389-6395. [CrossRef]

40. Du, S.S.L.; Jian, Y.; Wei, W.; Jia, S.; Biwu, C.; Wei, G. Potential of spectral ratio indices derived from hyperspectral LiDAR and laser-induced chlorophyll fluorescence spectra on estimating rice leaf nitrogen contents. Opt. Express 2017, 25, 6539-6549. [CrossRef]

41. Huang, R.; He, M. Band selection based on feature weighting for classification of hyperspectral data. IEEE Geosci. Remote Sens. Lett. 2005, 2, 156-159. [CrossRef]

42. Kavzoglu, T.; Mather, P.M. The role of feature selection in artificial neural network applications. Int. J. Remote Sens. 2002, 23, 2919-2937. [CrossRef]

43. Serpico, S.B.; Bruzzone, L. A new search algorithm for feature selection in hyperspectral remote sensing images. IEEE Trans. Geosci. Remote Sens. 2001, 39, 1360-1367. [CrossRef]

44. Cannavó, F. Sensitivity analysis for volcanic source modeling quality assessment and model selection. Comput. Geosci. 2012, 44, 52-59. [CrossRef]

45. Li, P.; Wang, Q. Retrieval of leaf biochemical parameters using PROSPECT inversion: A new approach for alleviating ill-posed problems. IEEE Trans. Geosci. Remote Sens. 2011, 49, 2499-2506.

46. Stocker, T.; Qin, D.; Plattner, G.; Tignor, M.; Allen, S.; Boschung, J.; Nauels, A.; Xia, Y.; Bex, B.; Midgley, B. IPCC, 2013: Climate change 2013: The physical science basis. In Contribution of Working Group I to the Fifth Assessment Report of the Intergovernmental Panel on Climate Change; IPCC: Geneva, Switzerland, 2013.

47. Ceolato, R.; Riviere, N.; Hespel, L. Reflectances from a supercontinuum laser-based instrument: Hyperspectral, polarimetric and angular measurements. Opt. Express 2012, 20, 29413-29425. [CrossRef]

48. Nevalainen, O.; Hakala, T.; Suomalainen, J.; Mäkipää, R.; Mikko, P.; Anssi, K.; Sanna, K. Fast and nondestructive method for leaf level chlorophyll estimation using hyperspectral LiDAR. Agric. For. Meteorol. 2014, 198, 250-258. [CrossRef]

49. Jian, Y.; Wei, G.; Shi, S.; Du, L.; Sun, J.; Zhu, B.; Yingying, M.; Shalei, S. Vegetation identification based on characteristics of fluorescence spectral spatial distribution. RSC Adv. 2015, 5, 56932-56935.

50. Wutzke, K.; Heine, W. A century of Kjeldahl's nitrogen determination. Z. Fur Med. Lab. 1984, 26, 383-388.

51. Paul-Limoges, E.; Damm, A.; Hueni, A.; Liebisch, F.; Eugster, W.; Schaepman, M.E.; Buchmann, N. Effect of environmental conditions on sun-induced fluorescence in a mixed forest and a cropland. Remote Sens. Environ. 2018, 219, 310-323.

52. Yegnanarayana, B. Artificial Neural Networks; PHI Learning Pvt. Ltd.: Delhi, India, 2009.

53. Lichtenthaler, H.K.; Rinderle, U. The role of chlorophyll fluorescence in the detection of stress conditions in plants. Crit. Rev. Anal. Chem. 1988, 19, S29-S85. [CrossRef]

54. Wang, Z.; Skidmore, A.K.; Wang, T.; Darvishzadeh, R.; Hearne, J. Applicability of the PROSPECT model for estimating protein and cellulose + lignin in fresh leaves. Remote Sens. Environ. 2015, 168, 205-218. [CrossRef]

55. Jacquemoud, S.; Baret, F. PROSPECT: A model of leaf optical properties spectra. Remote Sens. Environ. 1990, 34, 75-91. [CrossRef]

56. Zarco-Tejada, P.J.; Miller, J.R.; Pedrós, R.; Verhoef, W.; Berger, M. FluorMODgui: A graphic user interface for the spectral simulation of leaf and canopy fluorescence effects. In Proceedings of the 2nd International Workshop on Remote Sensing of Vegetation Fluorescence, Montreal, QC, Canada, 17-19 November 2004. 
57. Van der Tol, C.; Verhoef, W.; Timmermans, J.; Verhoef, A.; Su, Z. An integrated model of soil-canopy spectral radiances, photosynthesis, fluorescence, temperature and energy balance. Biogeosciences 2009, 6, 3109-3129. [CrossRef]

58. Yang, P.; van der Tol, C. Linking canopy scattering of far-red sun-induced chlorophyll fluorescence with reflectance. Remote Sens. Environ. 2018, 209, 456-467. [CrossRef]

59. Vilfan, N.; van der Tol, C.; Muller, O.; Rascher, U.; Verhoef, W. Fluspect-B: A model for leaf fluorescence, reflectance and transmittance spectra. Remote Sens. Environ. 2016, 186, 596-615. [CrossRef]

60. Celesti, M.; van der Tol, C.; Cogliati, S.; Cinzia, P.; Yang, P.; Francisco, P.; Uwe, R.; Franco, M.; Roberto, C.; Micol, R. Exploring the physiological information of Sun-induced chlorophyll fluorescence through radiative transfer model inversion. Remote Sens. Environ. 2018, 215, 97-108. [CrossRef]

61. Vilfan, N.; Van der Tol, C.; Yang, P.; Wyber, R.; Malenovský, Z.; Robinson, S.A.; Verhoef, W. Extending Fluspect to simulate xanthophyll driven leaf reflectance dynamics. Remote Sens. Environ. 2018, 211, 345-356. [CrossRef]

62. Muhammed, S.E.; Coleman, K.; Wu, L.; Bell, V.A.; Davies, J.A.; Quinton, J.N.; Carnell, E.J.; Tomlinson, S.J.; Dore, A.J.; Dragosits, U.; et al. Impact of two centuries of intensive agriculture on soil carbon, nitrogen and phosphorus cycling in the UK. Sci. Total Environ. 2018, 634, 1486-1504. [CrossRef]

63. Wan, Z. New refinements and validation of the collection-6 modis land-surface temperature/emissivity.product. Remote Sens. Environ. 2014, 140, 36-45. [CrossRef]

64. Wang, M.M.; Guojin, H.; Zhaoming, Z.; Guizhou, W.; Zhengjia, Z.; Xiaojie, C.; Zhijie, W.; Xiuguo, L. Comparison of spatial interpolation and regression analysis models for an estimation of monthly near surface air temperature in China. Remote Sens. 2017, 9, 1278. [CrossRef]

65. Wan, Z.; Dozier, J. A generalized split-window algorithm for retrieving land-surface temperature from space. IEEE Trans. Geosci. Remote Sens. 1996, 34, 892-905.

66. Zhengjia, Z.; Chao, W.; Hong, Z.; Yixian, T.; Xiuguo, L. Analysis of permafrost region coherence variation in the Qinghai-Tibet Plateau with a high-resolution TerraSAR-X image. Remote Sens. 2018, 10, 298. [CrossRef]

67. Genxu, W.; Guangsheng, L.; Chunjie, L.; Yang, Y. The variability of soil thermal and hydrological dynamics with vegetation cover in a permafrost region. Agric. For. Meteorol. 2012, 162, 44-57. [CrossRef] 